Community Organization's Intervention to promote community health for women in slum areas

Amal Mohammed Salameh Gobary (PhD) Department of Community Organization High Institute of Social Work - Alexandria 


\title{
Community Organization's Intervention to promote community health for women in slum areas
}

\author{
Amal Mohammed Salameh Gobary (PhD) \\ Department of Community Organization \\ High Institute of Social Work - Alexandria
}

\begin{abstract}
s
The study sought to verify the impact of a community organization's intervention to promote community health for women in slum areas. The study is based on the experimental method, using the experimental design of pre-test and post-test evaluations for two groups, the location for the implementation of the intervention program was applied in El-Amrawi health center in the Al-Montazah area, a Family Medicine Center under the Ministry of Health serving a large sector of women living in slum areas located in the Al-Montazah area. The study sample was selected according to the following conditions; firstly, women who frequent the El-Amrawi Health Center, one of the family medical centers that serves a segment of slum dwellers. Secondly, those Women have been frequenting the center for at least 6 months. Thirdly, they are mothers or are still in their pregnancy phase. Fourthly, they are willing to cooperate
\end{abstract} in the implementation of the program. Applying these conditions to those frequenting the center showed that the sampling framework was 410 women; a systematic random sample was 88 women, since they were divided into two groups, the experimental and the control, identical in properties with the number of the experimental and control groups being 44 each. The results of the study showed the positive impact of the community organization's intervention program to promote community health for women in slums areas through enriching their awareness of, and interest in, the environment, food, personal and reproductive health.

Key words: Community Organization, Community Health, Women, Slum Areas. 


\section{Introduction}

The challenge of slums is considered a global concern and a growing one. The rapid urbanization in the last century has been accompanied by tremendous growth of slum areas, currently, nearly one third of the developing world population and more than $60 \%$ of urban populations in the least developed countries live in slums (Unger A, 2013, p.799). The world population is expected to increase by 2 billion by 2030 (Pitcher H.M, 2009, p.1), approximately half of the population increase is estimated to be in urban slums (United Nation-Habitat, 2008, p. x). The United Nations (UN) operationally defines slums as having at least one of five characteristics: insecure residential status, poor structural quality of housing, overcrowding, inadequate access to safe water, and inadequate access to sanitation and other infrastructure (United Nation-Habitat, 2015, p.1). Slums have also been defined as diverse sets of communities, located centrally and in the periphery of cities, on floodplains and hillsides, and are poorly constructed (Davis M, 2006, p.228). The conditions of slum life are characterized by extreme poverty and exceedingly substandard living conditions, (United Nation-Habitat, 2003, p.1). Slums are the spatial manifestations of urban poverty, social exclusion, and inappropriate government policies.

Slums are uniformly characterized by inadequate provision of basic infrastructure and public services necessary to sustain health, such as water, sanitation, and drainage. Buildings made of flimsy materials are prone to ignite, frequently collapse, and offer scant protection against the elements, leaving their residents vulnerable to injury, violence, illness, and death. Furthermore, since many of these settlements are illegal, slum dwellers often have no official address and are commonly denied basic rights of public education, and health care, (Sclar E.D \& Northridge M.E, 2003, p.1381). Neglected populations living in poverty throughout the developing world are often heavily burdened by communicable and non-communicable diseases, and are highly marginalized by the health sector due to their limited access to health and social support services (Holveck J.C et al, 2007, p.1186).

Developing countries face dual obstacles to improve human health: a disproportionate burden of disease and a shortage of healthcare workers. So whilst improving health is an end in itself, it is 
also a means for achieving development goals and poverty reduction. Health is increasingly recognized as a central input into economic development and poverty alleviation, so it is important to develop community health, which is defined as a set of measures to provide health care to the population. Community health requires the participation of community members in the management of their individual and collective health. There is a notion of commitment from each individual, and community involvement is sought at all levels to action the following steps: analyzing the health status of the community, identifying problems, choosing priorities, defining the objectives and activities; mobilizing resources to improve precarious situations, organizing and conducting action, and evaluating the action (Faye A, Mand B, Fall A, 2013, p.1).

Based on the foregoing, we here refer to the importance of attention to health care programs provided to women, especially in slum areas, and the need to increase women's awareness of the rules and the foundations of community health. Women have the right to enjoy the highest attainable standard of physical and mental health. The enjoyment of this right is vital to their life and well-being and their ability to participate in all areas of public and private life. Health is a state of complete physical, mental and social well-being and is determined by the social, political and economic context of their lives, as well as by biology, however, health and well-being elude the majority of women (United Nations, 1995, p.38).

In the last two decades, women's health, as an interdisciplinary field, has grown significantly, as the demand for well-trained leaders and educators in the field has increased order to educate women in the basics of community health and how to look after their personal health. Women have specific health needs related to the sexual and reproductive function. Reproductive health, implies that wo me n are able to have a satisfying and safe reproductive life; implicit in this is the right of women to be informed of and to have access to comprehensive reproductive health care services that will enable them to go safely through the reproductive cycle including pregnancy and childbirth (Dall T.M, Chakrabarti R, Storm M.V, Elwell E.C, Rayburn W.F, 2013, p.643).

Lack of awareness of the extent and effect of reproductive morbidity on the health and quality of life of women in developing 
countries is evident at national, community and individual levels. Raising awareness at a national level requires population-based, epidemiological information, which must be validated. At a community level, public opinion mediates women's' actions when they are sick, and fear of social consequences provides a barrier to treatment. Individually, women find it difficult to talk about sexual reproductive health and its management (Graham W, Berer M, Price J, Brabin L, 1992, P.11). Also the protective health effects and other benefits of exclusive breastfeeding both for infants and mothers in developed and developing countries alike are well established. As a global public health strategy, the World Health Organization recommends that infants should be breastfed exclusively on breast milk for the first six months of age to achieve optimal growth, development and health, with continued breastfeeding up to two years of age and beyond (Booth I, 2001, p.625). Exclusive breastfeeding is associated with reduction in infant morbidity and mortality as well as improved growth (Froozani P.M, Permehzadeh K, Motlagh A.R, Golestan B, 1999, p.382), women's health awareness in the slum areas, and its impacts on community health, is important because women's health during the reproductive or fertile years (between the ages of 15 and 49 years) is relevant not only to women themselves, but also has an impact on the health and development of the next generation. Many of the health challenges during this period are ones that only young girls and women face. For example, complications of pregnancy and childbirth are the leading cause of death in young women aged between 15 and 19 years old in developing countries. Globally, the leading cause of death among women of reproductive age is HIV/ AIDS and the most important risk factors for death and disability in this age group, in low- and middle-income countries, are lack of contraception, and unsafe sex, resulting in unwanted pregnancies, unsafe abortions, complications of pregnancy and childbirth, and sexually transmitted infections including HIV. Violence is an additional significant risk to women's sexual and reproductive health and can also result in mental ill health and other chronic health problems. (World Health Organization, 2009).

There have been many previous studies focused on health care programs for women in slum areas and how they worked to improve the quality of health services. Some of those studies' results pointed to 
the substandard health conditions which women's suffered from in slum areas, and indicated that a significantly higher percentage of women living in slums came from country side, had a poorer status by household characteristics, had less access to mass media, and had less education than women not living in slums. (Khan M.M, Kraemer A, 2008, P.1). Another study found that women from slum areas depended on government facilities for reproductive health services, and the findings suggest that significant differences in reproductive health outcomes exist among women from slum and non-slum communities in India. Also, efforts to progress towards the health MDGs and other national or international health targets may not be achieved without a focus on the urban slum population. (Hazarika I, 2009 , p.264). Another study which aimed to determine the effectiveness of a health education program on raising knowledge related to breast cancer, confirmed the effectiveness of intervention programs in improving knowledge about breast cancer risk factors and practice of BSE, even in a group of women with a low literacy rate living in a slum area in Alexandria, Egypt (Kharboush I.F. et al, 2011, p.375). Another study reviewed the literature on health in the informal settlements (and "slums") that now house a substantial proportion of the urban population in Africa, Asia and Latin America. It notes how more gender- and age-sensitive strategies can help address the large inequalities in health between those in informal settlements and other urban residents. With greater attention to the multi-faceted needs of low-income communities, governments can create interventions to ensure that urban centers fulfill their enormous potential for good health (Sverdlik A, 2011, p.123). On the other hand, one research paper analyzed the state of health and access to health services among the urban poor in India. Analysis based on data from a primary survey conducted among 2000 households, covering 10,929 individuals from four cities of India, show a lack of government facilities and services, and econometric analysis of the determinants of acute illness indicates the insufficiency of basic amenities like sanitation, garbage disposal and potable water, together with the lack of availability of government health facilities in the vicinity. These results indicate continued vulnerability of the urban poor, and the need for urgent government action (Gupta I, \& Guin P, 2015, p.245). The results of one study targeted to improve reproductive and women's health in rural 
Bangladesh, as a controlled before and after study, showed that there were significant improvements in women's dietary diversity scores and participation in healthcare decision-making. Also, there were increases in knowledge about contraception, ways to treat and prevent sexually transmitted infections, nutrition and anemia prevention, and there were no significant differences in unmet needs for family planning, morbidity or night blindness. So the participatory women's groups have considerable potential to improve women's health knowledge. But evidence of impacts on certain outcomes is lacking, further formative work and intervention development is needed to optimize the impact of this approach for women's health, (Odeyemi A.O \& Nixon J, 2013, P.1).

Therefore, it is important to raise the health awareness of women in slum areas, in particular, to support the health levels of society. Here we refer to the role of the social work profession in dealing with issues related to community health and women's health, because professional social workers can provide services to individuals and families throughout their lives, addressing the full range of bio psychosocial-spiritual and environmental issues that affect well-being. Social work's strengths-based, person-inenvironment perspective provides the contextual focus necessary for client- and family-centered care, and is unique among the health professions (Cox L.E, Fritz T, Little V, Green S.o, Yamamoto A, 2016, p.5). The social work profession's involvement in public health dates back to the early 20th century, when social workers first worked in infectious disease control, maternal and child health, and settlement houses (Popple P. \& Leighninger L, 2004, P.21). Many public health social work programs were created during the second half of the 20th century, as roles expanded beyond direct services to include program administration, research, planning and evaluation, and advocacy (Gorin S.H, 2004, p.51). Because of their broad missions and multimethod approaches, social work and public health have both been challenged in their definition and conceptualization of professional practice (Gibelman M, 1999, P.298). Thus, the broad spectrum of functions and specializations in social work and public health contribute to definition-defying syntheses. Consequently, public health social work can be focused on any of the numerous essential functions of public health, making the diverse blending of roles a 
particular challenge. A public health social worker can be a researcher, policy analyst, program developer, provider of direct services, or administrator, (Association of Schools of Public Health, 2006). So many social workers in health settings have been engaged in public health social work without full cognizance of how they are defining, combining, or applying both skill sets. Some social workers find themselves formally or informally working in prevention due to the needs of the populations they serve, but may not recognize their work as part of public health. In order to improve awareness of public health social work (PHSW), a number of organizations are working to create and publicize a coherent set of public health social work definitions, standards, and competencies; incorporation of these into schools of social work and public health is clearly important, (American Public Health Association, 2006).

According to the context, community organizers use a wide variety of intervention strategies to promote social change. Social workers who engage in community organization practice often take on a variety of roles: they coordinate community outreach efforts, and link people to services (Donna H, 2002, P.19), so community organization intervention can help to raise women's awareness of health issues. Therefore, community organizers must depend on the "application of practice skills to alter the behavioral patterns of community groups, organizations, and institutions or people's relationships and interactions with these entities." Furthermore, community practice, as part of macro-practice, includes the techniques associated with community organization and development, social planning and social action, and social administration (Hardcastle D.A, Wenocur S, powers P.R, 1997, p.1).

Many practitioners and academics use the terms "community" and "macro" practice interchangeably; for example, Gamble and Weil (2010) describe community practice social work as encompassing multiple areas of practice, including organizing, sustainable development, planning, and progressive change (p.91). This manuscript will follow Netting's (2008) definitions, using "macro practice" to refer to the breadth of practice with larger systems, "community practice" to refer to practice specifically with communities and neighborhoods, "administrative practice" to refer to 
work with organizations and agencies, and "policy practice" to refer to legislative and governmental advocacy. (p.230)

So community organization considered a process by which a community identifies its needs or objectives, orders (ranks) them, develops the confidence to work at these needs or objectives, finds the resources (internal and /or external) to deal with them, takes action in respect to them, and, in so doing, extends and develops co-operative and collaborative attitudes and practices in the community (Ross M.G, 1955 , p.41).So when community organizers work with women's health centers, they must define women's health needs, and the resources which can be used to meet those needs, and find a channel to work through it to raise women's awareness of food, environmental, personal and reproductive health. The community organizer must depend on changing the behaviors of women's in slum areas, and give them more information's and knowledge about the right way to care about their health, not just for herself but also for her children. The community organization method is considered a process of changing the behavior of the community's population, improving their abilities to grow and take better care of themselves (Sanders I.T, 1960, p.51). And a community organizer works to meet community members' needs, matching resources and needs, and working to help people deal more effectively with their problems and achieve their goals by helping them to develop and strengthen participation, cooperation and self-guidance (Dunham A,1970, p.146). Community organizing is a comprehensive process for managing change within a community by involving citizens in dialogues on shared vision and the salient issues of strategy design and implementation. A framework consisting of four characterizations for understanding the concept of community development is based on several definitions. These characterizations explain community development as (a) a process for implementing change, (b) a program of specified activities, (c) an outcome, and (d) an ideology of action. Hence, community development is a means to bring forth positive change. By implementing positive changes, such as needs-specific programs and through their grassroots involvement, the community development process can be achieved through the incorporation of communal techniques for addressing health issues and by investing in infrastructure such as support groups and medical services, (Morton L.W \& Glasgow N, 2011, p.234) 
Within this context, community organization can contribute to developed health consciousness; it can contribute to the strengthening the attitudes and values of positive healthy behaviors. This study monitors the consequences of community organization intervention to promote community health for women in slums areas

\section{Methodology}

Hypothesis: The Main hypothesis: "There are statistically significant differences between the average of pre-post measurement's degrees when using the intervention program and promoting community health for women in slum areas for the post measurement."

\section{Sub-hypotheses}

- There are statistically significant differences between the average of pre-post measurements degrees when using the intervention program and promoting the interest of environmental health for women in slum areas for the post-measurement.

- There are statistically significant differences between the average of pre-post measurements degrees when using the intervention program and promoting the interest of food health for women in slum areas for the post-measurement.

- There are statistically significant differences between the average of pre-post measurements degrees when using the intervention program and promoting the interest of personal health for women in slum areas for the post-measurement.

- There are statistically significant differences between the average of pre-post measurements degrees when using the intervention program and promoting the interest of reproductive health for women in slum areas for the post-measurement.

\section{Participant:}

- Type of study and methodology used: This study is considered one of the estimating studies of intervention, targeting the evaluation of the impact of an independent variable (intervention program by community organization method), on a dependent variable (promoting community health for women in slum areas). The study is based on the experimental method, using the experimental design of pre- and post-test evaluations for two groups. The first one is an experimental group and the other is a control group. A pre-test evaluation was conducted for both groups (experimental 
and control)prior to the intervention. Then, the Intervention Program (independent variable) was conducted on the experimental group only. Then a post-test evaluation was conducted on both the experimental and control groups, (refer to table "1", which shows pre and post-test evaluations for both experimental and the control groups). On comparing the results of both evaluations, the size of the current change is determined. The study also relied on a social survey with systematic random sampling.

Table (1) shows the measurement pre and post for the two experimental and control group for the study sample

\begin{tabular}{|c|c|c|c|c|c|c|}
\hline \multirow{3}{*}{$\begin{array}{c}\text { Scale } \\
\text { Variables }\end{array}$} & \multicolumn{4}{|c|}{ Before Intervention } & \multirow{2}{*}{\multicolumn{2}{|c|}{\begin{tabular}{|c|} 
After Intervention \\
Experimental \\
Group \\
\end{tabular}}} \\
\hline & \multicolumn{2}{|c|}{$\begin{array}{c}\text { Experimental } \\
\text { Group }\end{array}$} & \multicolumn{2}{|c|}{ Control Group } & & \\
\hline & Mean & S.D & Mean & S.D & Mean & $\begin{array}{l}\text { S.D } \\
\end{array}$ \\
\hline Environmental Health & 1.93 & 0.24 & 1.93 & 0.23 & 2.44 & 0.19 \\
\hline Food Health & 2.02 & 0.36 & 2.02 & $\begin{array}{ll}0.34 \\
\end{array}$ & 2.66 & 0.29 \\
\hline Personal Health & 2.15 & $\mathbf{0 . 3 2}$ & 2.14 & 0.31 & 2.76 & 0.27 \\
\hline Reproductive Health & 2.23 & 0.40 & 2.22 & 0.39 & 2.69 & 0.30 \\
\hline
\end{tabular}

- Spatial domain and study sample: the location for the implementation of the intervention program was determined as ElAmrawi Health Center in Al- Montazah area. This is a Family Medicine Center under the Ministry of Health which serves a large sector of women living in slum areas that are located in AlMontazah area.

- The study sample was selected according to the following conditions: firstly, women who frequent the El-Amrawi Health Center, one of the family medical centers that serve a segment of slum dwellers. Secondly, those women have been frequenting the center for at least 6 months. Thirdly, they are mothers or are still in their pregnancy phase. Fourthly, they are willing to cooperate in the implementation of the program. Applying these conditions on those frequenting the center showed that the sampling framework was 410 women. A systematic random sample was drawn from a list in which the names of these women were mentioned. The study sample became 88 women since they were divided into two groups, the experimental and the control, identical in properties where the number of the 
experimental and control groups was 44 each.

\section{Intervention:}

The goals of the intervention program: The intervention program aims to achieve the objectives of the current study, which is are to promote interest in the mechanisms of community health for women in slum areas through the practicing of the intervention program by the community organization method, and working on training participating women in the intervention program, supplying them with knowledge, skills and expertise in the field of community health. The Work Team participating in the intervention program comprises the researcher, experts and specialists in the medical health community, some of the Ministry of Health trainers, and social workers.

Timing of professional intervention program: Duration of the program: 12 weeks, Number of days of the program: 24, Number of interviews per week: 2 (theoretical - practical), Session time: two hours, number of program hours: 48 . (Theoretical 24 hours - Practical 24 hours).

\section{Phases of the application of professional intervention program.}

(A) The study phase, which includes: Determining the form of intervention through the collection of information, data and their activities and community programs, Contacting leadership of the center and explaining the subject of the study and its objectives and obtaining approval for the implementation of the program, Determining the center's physical and human resources and how to use them in the implementation of the program, Identifying the members of the team working as specialists in community medicine, psychologists and specialists meetings, and trainers from the Ministry of Health, specialists in community health as assistants for the researcher in the application of the program.

(B) Planning Phase, this includes identifying procedural objectives sought by the program. Putting a time schedule in place for the implementation of the program, in which is specified the number of hours, days, weeks and months, while highlighting the content of the program. Making contact with experts and specialists with whom to collaborate in the implementation of the program, and formulation of the objectives of the program. Determining the theory and content of the program related to the community organization 
method. Defining roles and responsibilities in order to avoid overlapping of responsibilities with others in the implementation of the program. Developing of indices for measuring in light of the intervention benefit as output.

(C) The Implementation phase, which includes Implementation of the time schedule for intervention through professional and academic efforts by holding multiple meetings with health center leaders about the implementation of the program Conducting of pre-test measurement for the intervention program The application of the intervention program - Overcoming difficulties and obstacles to the implementation of the program during its implementation.

(D) The evaluation phase, which Includes conducting posttest measurement, evaluating the program in terms of Content Schedule plan - Method - shortcomings. Testing validity of the study hypotheses. Extraction of the general findings and formulation of recommendations.

The scientific content of the intervention program: The contents of the training program was determined by relying on scientific and theoretical literature in the training subject, as well as determining the topics in light of the actual needs of the trainees, with the assistance of experts and specialists, The scientific content includes the following themes: Scientific, medical and facts of life associated with the promotion of environmental health, and Scientific, medical and facts of life associated with the promotion of food health, and Scientific, medical and facts of life associated with the promotion of personal health, and Scientific, medical and facts of life associated with the promotion of reproductive health.

\section{Measures:}

The researcher prepared a measurement for promoting community health for women in slum areas, in light of the following steps:

- Collecting and formulating statements phase: During this phase, a number of phrases related to the subject of the study and its indices were collected. The researcher relied on several sources: viewing the theoretical heritage and previous studies on variables of the study, interviewing specialists in social work, and experts in the field of community health medicine, identifying four 
indices for the scale for each aspect of community health.

- Measurement Arbitration phase: The researcher presented the measurement in its initial form to arbitrators from varied specialties in order to make sure of: linguistic soundness of each phrase, and the extent to which the phrase is related to the subvariable, also the extent to which the phrase is related to the subject of the study, as well as to add any other phrase which arbitrators regard as important to the measurement topic. The researcher has made an inventory of all the notes of deletions and additions, and 15 statements that were not agreed upon by $80 \%$ of the arbitrators were deleted that therefore the measurement was limited, following the arbitration, to 55 phrases.

\section{Measurement Reliability:}

- The researcher calculated reliability by re-testing a 10 -individual sample, within a time interval of 15 days between the first test and the second. The results of reliability on the scale as a whole and its dimensions $=(0.80)$. This means that the measurement is of a high degree of stability.

- This significance is confirmed by the significance of test Cronbach's alpha correlation on all the dimensions of the scale and degree of stability where the distribution of the two tests (the first and second) is as follows: (First variable $=0.895$, Second variable $=0.853$, Third variable $=0.856$, Fourth variable $=0.85$, Scale as a whole $=0.80$ ) Thus, the general index of stability = (0.80), which is a high - stability index.

\section{Measurement validity:}

- Arbitrator's validity: The measurement was presented to a group of arbitrators specializing in social work. They examined it and expressed their opinions about the appropriateness of the measurement indices and the statements or phrases used for the study objectives. They ensured the soundness and good formulation of the phrases so that they would give a precise and clear description to the performance to be measured. After applying their amendments and suggestions, the phrases that the arbitrators decided that they should be excluded (and which did not get the approval of $80 \%$ of the arbitrators) were eliminated

- Validity of internal consistency: The measurement was applied in its final form on a sample of (10) individuals. The individuals' correlation coefficients to the index to which it belongs were 
calculated. also the correlation coefficients between the dimensions of the measurement and the total score were calculated.

Table (2) shows the correlation between dimensions of measurement

\begin{tabular}{|c|c|c|c|c|}
\hline Dimensions & $\begin{array}{c}\text { Environmental } \\
\text { Health } \\
\end{array}$ & Food Health & $\begin{array}{c}\text { Personal } \\
\text { Health }\end{array}$ & $\begin{array}{c}\text { Reproductive } \\
\text { Health } \\
\end{array}$ \\
\hline $\begin{array}{c}\text { Environmental } \\
\text { Health }\end{array}$ & 1 & & & \\
\hline Food Health & 0.75 & 1 & & \\
\hline Personal Health & 0.77 & 0.87 & 1 & \\
\hline $\begin{array}{l}\text { Reproductive } \\
\text { Health }\end{array}$ & 0.81 & 0.71 & 0.81 & 1 \\
\hline Total & 0.77 & 0.79 & 0.81 & 0.80 \\
\hline
\end{tabular}

Measurement correction: A trilateral gradation was used so that the response to each phrase is (yes - to some extent - no). For each response, the following weights $\{1-2-3\}$ consecutively were given to the positive phrases and the opposite to the negative phrases. The maximum grade for the entire measurement reached 132 and the middle grade of the measurement was 88. As for the minimum grade of the measurement as a whole, it reached 44 .

Statistical Analysis: The study relied on percentages, relative weights analysis, and RSI to estimate respondent's responses about the variables of the study, as well as calculating the ratio of agreement for the sincerity of the arbitrators. This is in addition to the alpha Cronbach's coefficient for the detection of the correlation relationships between the scale dimensions and finding the value of the scale stability coefficient by re- application. There is also the $t$ test that is used in order to find the differences and their significance between the pre- and post-test measurement. The researcher used the statistical programs SPSS package/PC-V.18 in calculating the value of the previous statistical transactions. 


\section{Results}

(1) Results of the first sub - hypothesis of the study:

Table (3) show the significance differences between the measurement before and after to enhance interest in environmental health

\begin{tabular}{|c|c|c|c|c|c|c|c|}
\hline \multicolumn{2}{|c|}{$\begin{array}{c}\text { Before } \\
\text { Intervention }\end{array}$} & \multicolumn{2}{|c|}{$\begin{array}{c}\text { After } \\
\text { Intervention }\end{array}$} & \multicolumn{2}{|c|}{ R.S } & \multirow{2}{*}{$\begin{array}{l}(\mathrm{T}) \\
\text { test }\end{array}$} & \multirow{2}{*}{ Significance } \\
\hline$\overline{~ M e a n ~}$ & 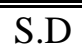 & $\overline{~ M e a n ~}$ & S.D & $\overline{\text { Before }}$ & After & & \\
\hline 1.93 & 0.24 & 2.44 & 0.19 & $64.7 \%$ & $81.6 \%$ & 4.440 & significant \\
\hline
\end{tabular}

Results of Table (3) show the existence of statistically significant differences between averages of pre and post-test measurements in favor of the post - test measurement when using the intervention program to promote interest in environmental health for women in slums areas .The arithmetic average of the pre-test measurement reached (1.93) with a standard deviation of (0.24), while it has reached (2.44) with a standard deviation of (0.19) after professional intervention. Results also show that the relative strength before the intervention in the pre-test measurement is $(64.7 \%)$, while it becomes $(81.9 \%)$ in the post -test measurement. This indicates the positive impact of the content of the intervention program, the roles, strategies, professional techniques and means, used to promote environmental awareness for women.

(2) Results of the sub - second hypothesis of the study:

Table (4) show the significance differences between the measurement before and after to enhance interest in the food health

\begin{tabular}{|c|c|c|c|c|c|c|c|}
\hline \multicolumn{2}{|c|}{$\begin{array}{c}\text { Before } \\
\text { Intervention }\end{array}$} & \multicolumn{2}{|c|}{$\begin{array}{c}\text { After } \\
\text { Intervention }\end{array}$} & \multicolumn{2}{|c|}{ R.S } & \multirow{2}{*}{$\begin{array}{l}(\mathrm{T}) \\
\text { test }\end{array}$} & \multirow{2}{*}{ Significance } \\
\hline Mean & S.D & Mean & S.D & Before & After & & \\
\hline 2.02 & 0.36 & 2.66 & 0.29 & $67.6 \%$ & $88.7 \%$ & 3.371 & significant \\
\hline
\end{tabular}

Results of Table (4) show the existence of statistically significant differences between averages of pre- and post-test measurement in favor of the post -test measurement when using an intervention program to promote interest in food health for women in slum areas". The arithmetic average of the pre-test measurement is (2.02) with a standard deviation of (0.36), while it reaches (2.66) with a standard deviation of (0.29) after intervention. Results also show that the relative strength of pre-intervention in pre-test measurement is $(67.6 \%)$, while it becomes $(88.7 \%)$ in post-test 
measurement, which indicates the positive impact of the content of the intervention program, the roles, strategies, professional techniques and means, used to promote awareness of food health for women.

(3) Results of the third sub - hypothesis of the study:

Table (5) Show the significance differences between the measurement before and after to enhance interest in personal health

\begin{tabular}{|c|c|c|c|c|c|c|c|}
\hline \multicolumn{2}{|c|}{$\begin{array}{c}\text { Before } \\
\text { Intervention }\end{array}$} & \multicolumn{2}{|c|}{$\begin{array}{c}\text { After } \\
\text { Intervention }\end{array}$} & \multicolumn{2}{|c|}{ R.S } & \multirow{2}{*}{$\begin{array}{l}(\mathrm{T}) \\
\text { test }\end{array}$} & \multirow[t]{2}{*}{ Significance } \\
\hline Mean & S.D & Mean & S.D & Before & After & & \\
\hline 2.15 & 0.32 & 2.76 & 0.27 & $71.9 \%$ & $92.1 \%$ & 3.625 & icant \\
\hline
\end{tabular}

Results of Table (5) show the existence of statistically significant differences between averages of pre- and post-test measurements in favor of the post-test measurement by using intervention program to promote interest in Personal health for woman in slum areas. The arithmetic average of the pre-test measurement is (2.15) with a standard deviation (0.32), while it reaches (2.76) with a standard deviation of (0.27) after intervention. Results also show that the relative strength of pre- intervention in pretest measurement is $(71.9 \%)$, while it becomes $(92.1 \%)$ in post-test measurement, which indicates the positive impact of the content of the intervention program, the roles, strategies, professional techniques and means, used to promote awareness of personal health for women.

\section{(4) Results of the fourth sub - hypothesis of the study:}

Table (6) show the significance differences between the measurement before and after to enhance interest in reproductive health

\begin{tabular}{|c|c|c|c|c|c|c|c|}
\hline \multicolumn{2}{|c|}{$\begin{array}{c}\text { Before } \\
\text { Intervention }\end{array}$} & \multicolumn{2}{|c|}{$\begin{array}{c}\text { After } \\
\text { Intervention }\end{array}$} & \multicolumn{2}{|c|}{ R. } & \multirow{2}{*}{$\begin{array}{l}(\mathrm{T}) \\
\text { test }\end{array}$} & \multirow{2}{*}{ Significance } \\
\hline Mean & S.D & Mean & "S.D & Before & After & & \\
\hline 2.23 & "0.40 & 2.69 & 0.30 & $74.7 \%$ & $89.7 \%$ & 3.707 & icant \\
\hline
\end{tabular}

Results of Table (6) show the existence of statistically significant differences between averages of pre- and post-test measurements for the favor of post-test measurement by using intervention program to promote interest in reproductive health for woman in slum areas. The arithmetic average of the pre-test measurement is (2.23) with a standard deviation (0.40), while it reaches (2.69) with a standard deviation (0.30) after intervention, Results also show that the relative strength of pre- intervention in pre- 
test measurement is $(74.7 \%)$, while it becomes $(89.7 \%)$ in the post-test measurement, which indicates the positive impact of the content of the intervention program, the roles, strategies, professional techniques and means, used to promote awareness of reproductive health for women.

\section{Discussion:}

This study is considered one of the estimating studies of intervention, targeting the evaluation of the impact of an independent variable (intervention program by community organization), on a dependent variable (promoting community health for women in slum areas). The main hypothesis of the study was "There are statistically significant differences between the average of pre-post measurements degrees when using the intervention program and promoting community health for women in slum areas for the post measurement" The intervention program aims at achieving the objectives of the current study, which is to promote the interest in the mechanisms of community's health for women in slum areas through the practice of the intervention program by the community organization method, and working on training participating women in the intervention program, supplying them with knowledge, skills and expertise in the field of community health.

The study results, on the promotion of community health for women in slum areas, match to the results of the studies tackling the impact of women's involvement in environmental management. Appropriate recommendations were proffered to enhance women's involvement in environmental protection and management (Wuyeb S.Z, Dung V.C, Buhari A.H, Madaki D.H, Bitrus B.A, 2014, p.32). Women who are trying to conceive do not have a significantly higher nutrition awareness than women who are not trying to conceive, so conceptualization of nutrition awareness has shown to be fruitful in obtaining a better understanding of behavioral changes in health. Pregnancy could indeed be an event in a woman's life that causes increased nutrition awareness, this should be kept in mind when healthy nutrition promotion activities are being developed (Szwajcer E, Hiddink G.J, Maas L, Koelen M, Woerkum V.C, 2012, p.82). Awareness of reproductive health is poor in Egypt, even among young women attending institutions of higher education. We must not only 
highlight the persistent need for the ongoing reproductive health information programs, but may also provide policy makers with data that will inform new strategies (El Gelany S. \& Moussa O, 2012, p.375). Through the success of the community organization intervention program, we can clarify the importance of intervention programs that aim to increase women's awareness of the community health concept and mechanisms, especially in slums areas to support a healthy culture, and working to promote a healthy level of society as a whole.

The study results of the intervention program, match to the results of a study tackling the impact of health education intervention for increasing women's knowledge of health issues. Its result show that the intervention raised the level of awareness of cervical cancer and screening among women, and the proportion of women with very good knowledge of cervical cancer and screening rose while the proportion of those with good perception rose; the mean knowledge and mean perception scores were also increased. There was an increase in the proportion of women who undertook cervical screening. The major reason stated by the women for not having had cervical screening done was lack of awareness about cervical cancer and screening. (Abiodun O.A, Olu-Abiodun O.O, Sotunsa J.O, Oluwole F.A, 2014, p.1). Another study took into account community beliefs when the intervention program was applied for raising awareness and knowledge of women's health, because different communities interpreted and responded differently and sometimes in unexpected ways according to community culture (Brown K, Beecham D, Barret H, 2013, p.1)

On the other hand, some studies agree with the results of the current study and emphasis the importance of intervention. Its results show that the intervention was effective in knowledge gain for all groups of women, particularly for raising awareness of heart disease as the leading killer in American Indians (Amparo V.C, Christina S, Liana L, Daniel T, 2016, p.1). Another study demonstrated that awareness of tuberculosis, as a disease is relatively low among women living on the geographical coastline of the Atlantic Ocean in Lagos. It is important to continue sustained efforts to increase awareness and motivation for proper contraceptive use because of the low knowledge level of women (Al Sheeha M, 2010, p.11). The level of awareness 
among Arab women about reproductive and sexual health of women is still limited, therefore, it is necessary to raise the level of women's awareness of all information and guidance on reproductive and sexual health, and we should point out the importance of education in raising the level of health education for Arab women (Sharif A, 2012, p.39). Also, women need to be aware of the importance of family planning to reduce risks to the health and lives of mothers and children. On the other hand, there is a study that shows that it is important to raise the awareness level of women of the negative impact of Female Genital Mutilation, and how to achieve sexual safety as well as provide guidance on reproductive health (Ragab A.R, Fahmy A, Al- Muhaili M,Uhansan A, 2012, p.1). Also there is a study which emphasizes the importance of spreading health awareness among youth, and activating health education programs on health (Sharif A, 2011, p.25). Therefore, we must increase the participation of couples in reproductive health awareness and women's health programs, because the awareness of couples contributes to increased women's health care indicators and actual achievement of women's care (Al-Agamy M.F \& Rizk I.A, 2011, p.1085).

There is a need to provide health care for women during pregnancy and childbirth in health centers, mother and childhood care centers, and health units, with a concern to educate mothers about the importance of breastfeeding and ways to care for mother and child. Our search highlights the need for the professional intervention of a community organization method to activate women's health awareness programs, and the results confirm the need for social work research to fill gaps and more fully address the needs of women throughout their lives (Bird M, Wright R.L, Frost C.J, 2016, p.732).

So health promotion is very relevant today. There is a global acceptance that health and social well-being are determined by many factors outside the health system which include socioeconomic conditions, patterns of consumption associated with food and communication, demographic patterns, learning environments, family patterns, the cultural and social fabric of societies; sociopolitical and economic changes, including commercialization, trade and global environmental change. In such a situation, health issues can be effectively addressed by adopting a holistic approach by empowering individuals and communities to take action for their health, fostering 
leadership for public health, promoting inter oral action to build healthy public policies in all sectors and creating sustainable health systems (Kumar S \& Preetha G.S, 2012, p.5).

\section{Recommendation:}

The study recommends that social workers must commit themselves to enhancing the well-being of women through an intervention program of a community organization, to raise and promote women's awareness of community health as an essential aspect of the profession's ethical and practice commitment to human rights. And community social workers must be involved in the broadest range of professional activities that are critical to the wellbeing of women. Specific efforts include the delivery of health care services and public health programs. The study also recommends more studies in the fields of women's health and community health (including the training of social workers in the health field to activate community health programs), the importance of studying the role of education and health awareness, the creation of mother and child centers in slum areas to activate the systems which provide services for women and children in slums, and the need to promote social work in the health field to set up conferences, seminars and workshops that are focused on women's health issues and community health programs.

\section{Limitations:}

The author faced some difficulties upon performing the study including: The low economic and cultural level in the slum areas meant the author spent a period of time in order to convince the ladies to attend the private meetings Intervention Program. Also the long period required for performing the study, the program ran for twelve weeks. Requirements for application of intervention program, and the physical requirements, which include identification of halls, tools and technological means to communicate with the working groups. Human requirements, which include doctors in community health, social worker and psychologist, trainers from the Ministry of Health. Finally, the training requirements, which include the preparation of scientific content, and sessions with members of the teamwork.

Acknowledgements: The author would like to express his gratitude to team work in this study, doctors in community health, social worker and psychologist, trainers from the Ministry of Health, also gratefully 
acknowledge the contributions of reviewers for their constructive comments.

\section{Reference}

Abiodun, O.A., Olu Abiodun, O.O, Sotunsa, J.O, Oluwole,F.A. (2014). Impact of health education intervention on knowledge and perception of cervical cancer and cervical screening uptake among adult women in rural communities in Nigeria, BMC Public Health, DOI: 10.1186/1471-2458-14814.

Al Sheeha, M. (2010). Awareness and use of contraceptives among Saudi women attending primary care centers in Al-Qassim, Saudi Arabia, Int J Health Sci (Qassim). Jan; 4(1): 11-21. PMCID: PMC3068803.

Al-Agamy, M.F \& Risk, I.A. (2011). Husbands behavior concerning family planning and its relation to some variables in a village of Dakhlia Governorate, Egypt, J. Agric Economic and Social Sci, Mansoura University, vol.(2),(8),pp:1085-1098

American Public Health Association. (2006). Social work section newsletter. Retrieved April 14, 2016. http://www.apha.org/ membergroups/ newsletters/sectionnewsletters /social/spring6

Amparo, V. C., Christina, S., Liana, L., Daniel, T. (2016). Ooutcomes' of a clinic-based educational intervention for cardiovascular disease prevention by Race, Ethnicity, and Urban/Rural Status, Journal of Women's Health. November, 25(11), pp: 1174-1186. doi:10.1089/jwh.2015.5387.

Association of Schools of Public Health (2006). Other public health fields. Retrieved April 2016, from http://www.asph.org/ document.cfm?page=707.

Bird, M., Wright, R.L., Frost, C.J. (2016). Enhancing women's health: a call for social work research. Journal of social work in health care, vol (55), issue (9), pp.: 732-751.

Booth , I (2001). Does the duration of breast feeding matter?, British Medical Journal 322: 625-625. doi: https://doi.org/10.1136/ bmj.322.7287.625.

Brown, K., Beecham, D, Barrett, H. (2013). The applicability of behavior change in intervention programs targeted at ending female genital mutilation in the EU: integrating social cognitive and community level approaches, Obstetrics and Gynecology International, Volume 2013 (2013), Article ID 324362, 12 pages. http://dx.doi.org/10.1155/2013/324362.

Cox, L.E., Fritz, T., Little, V., Green, S.O, Yamamoto, A. (2016). NASW standards for social work practice in health care setting, National Association of Social Workers, USA.

Dall, T.M., Chakrabarti, R., Storm, M.V, Elwell, E.C., Rayburn, W.F. (2013)." Estimated demand for women's health services by 2020", Journals of Women's Health 2013. 22:643-648

Davis, M. (2006). Planet of slums. London, New York: Verso. 
Donna, H. (2002). Analytical skills for community organization practice, Columbia University Press, 2002, pp. 17 - 43.at http// www.jstor.org/stable/10.7312/hard12180.6.

Dunham, A. (1970).The new community organization, N.Y. McGraw-Hill. El Gelany, S. \& Moussa, O. (2012). Reproductive health awareness among educated young women in Egypt, International journal of gynecology and obstetrics: the official organ of the International Federation of Gynecology and Obstetrics ,(120), (1) - DOI: 10.1016/j.ijgo.2012.07.027 .

Faye, A., Mand, B. and Fall, A. (2013). Can the community health constitute a Means of Fight against social inequalities of health? case of senegal, J Biosafety Health Educ 2013, 1:4. http://dx.doi.org/10.4172/23320893.1000107.

Froozani, P. M., Permehzadeh, K., Motlagh, A.R., and Golestan, B. (1999). Effect of breastfeeding education on the feeding pattern and health of infants in their first 4 months in the Islamic Republic of Iran, Bulletin of the World Health Organization, 77 (5), 381-385.

Gamble, D., \&Weil, M. (2010). Community practice skills: local to global perspectives. New York: Columbia University Press.

Gibelman, M. (1999). The search for identity: defining social work-past, present, future. Social Work, 44, pp.: 298-310. DOI: https://doi.org/10.1093/sw/44.4.298.

Gorin, S. H. (2001).The crisis of public health: implication for social workers. Health and Social Work, 26, pp.: 49-53.

Graham, W., Berer, M., Price, J., an Brabin, L. (1992). Raising awareness about reproductive morbidity", Annals of Tropical Medicine \& Parasitology, Vol. 86, Iss. Sup1, pp.:11-18.

Gupta, I. \& Guin , P. (2015)." Health status and access to health services in Indian slums", Health, vol (7), pp.:245-255. DOI: 10.4236/health.2015.72029.

Hardcastle, D.A., Wenocur,S., Powers, P.R. (1997). Community practice: theories and techniques for social workers. New York: Oxford University Press.

Hazarika, I. (2009). Women's reproductive health in Slum Populations in India: evidence from NFHS-3, journal of urban health, bulletin of the New York academy of medicine, vol (87), no (2), pp.:264-277. DOI: $10.1007 / \mathrm{s} 11524-009-9421-0$.

Holveck J.C., Ehrenberg J.P., Ault S.K., Rojos R., Vasquez J., Cerqueira M.T., Shepherd J.I., Genovese M.A. \& Periago M.R. (2007). Prevention, control, and elimination of neglected diseases in the Americas: pathways to integrated, inter- programmatic, inter sectorial action for health and development. BMC Public Health 7: 6. DOI: 10.1186/1471-2458-7-6.

Khan, M.M. and Kraemer, A. (2008). "Socio-economic factors explain 
differences in public health-related variables among women in Bangladesh: A cross-sectional study", BMC Public HEALTH, Bio Med Central, pp:110.Doi:1186/1471-2458-8-254.

Kharboush, I.F., Ismail, H.M., Kandil, A.A, Mamdouh, H.M., Muhammad, Y.Y., Elsharkawy, O.O., Sallam, H.N. (2011). Aising the breast health awareness amongst women in an urban slum area in Alexandria, Egypt, Breast Care, vol.(6), pp. :375-379. DOI: 10.1159/000331311.

Kumar, S. \& Preetha, G.S. (2012). Health promotion: an effective tool for global health, Indian J Community Med, Jan-Mar; vol .37, no.(1) pp.: 512.doi: 10.4103/0970-0218.94009.

Morton, L.W. \& Glasgow, N. (2011). Health: a new community developmental-lenge. In J. W. Robinson \& G.P. Green (Eds), Introduction to community development: theory, practice, and service-learning .Thousand Oaks, CA: Sage.

Netting, F. (2008). Macro social work practice. In T. Mizrahi \& L. Davis (Eds.), The encyclopedia of social work. National Association of Social Workers and Oxford University Press, Inc. Retrieved from: $\mathrm{http} / / / \mathrm{www} .0 x f o r d r e f e r e n c e . c o m / v i e w s / E N T R Y$. html? Subview $=$ Main\&entry $=\mathrm{t} 203 . \mathrm{e} 230$.

Odeyemi, A.O. \& Nixon, J. (2013). Assessing equity in health care through the national health insurance schemes of Nigeria and Ghana: a review-based comparative analysis, In $\mathrm{J}$ Equity in Health, 12: 9, p.1- 18. DOI: $10.1186 / 1475-9276-12-9$.

Pitcher H. M. (2009). The future of scenarios: issues in developing new climate change scenarios, Environmental Research Letters; (4), 2 (025002), pp.:1-7.doi:10.1088/1748-9326/4/2/025002.

Popple, P. R., \& Leighninger, L. (2004). Social work, social welfare and American society. Boston: Allyn \& Bacon.

Ragab, A.R., Fahmy, A., Al-Muhaili, M., Uhansan, A. (2012). The relationship between women's sexuality and female genital mutilation: a descriptive study in three local societies in Egypt, Arab Family Health and Population Magazine, League of Arab States, Volume V, Issue 13, January, pp. 1-37.

Ross, M.G. (1955). Community organization, theory and principles, N.Y, Harper and Brothers.

Sanders, I.T. (1960). What makes a good community in our community, N.Y, University Press.

Sclar, E.D. \& Northridge, M.E. (2003). American Journal of Public Health, vol (93), issue (9),:1381.

Sharif, A. (2011) .Youth and health education in reproductive health issues and preparing them for the reproductive role in the Arab region (comparative 
study), Arab Family Health and Population Magazine, League of Arab States, Volume IV, Issue 11, May, pp. 25- 56.

Sharif, A. (2012). The reality of reproductive and sexual health in the Arab countries from the results of the Arab survey of family health, Arab Family Health and Population Magazine, League of Arab States, Volume V, Issue 13, January, pp. 39-69.

Sverdlik, A. (2011)."Ill-health and poverty: a literure review on health in informal settlements", Environment \&Urbanization, vol (23), no (1), pp: 123-155. DOI: 10.1177/0956247811398604.

Szwajcer, E., Hiddink, G.J., Maas, L., Koelen, M.,Woerkum,V.C. (2012). Nutrition awareness before and throughout different trimesters in pregnancy: a quantitative study among Dutch women, Fame Pact, 29 (suppl_1): I 82- I 88. DOI:https://doi.org/10.1093/fampra/cmr107.

Unger, A. (2013). "Children's health in slum settings", Archives of disease in childhood, BMJ journals, vol.(98), no(10),:pp799-805 http://dx.doi.org/10.1136/archdischild-2011-301621.

United Nation- HABITAT (2003). UNHSP the challenge of the slums: global report on human settlements, Nairobi, United Nations, 2003. At http://www.unhabitat.org/downloads/docs/GRHS.2003.0.Pdf(accessed 3 may 2016).

United Nation-HABITATT.(2015). Housing and slum upgrading. Retrieved on May 24, 2016 at: http://unhabitat.org/ urban- themes/ housingslum-upgrading/.

United Nations. (1995), Report of the fourth world conference on women. Beijing, 4-15 September 1995. Paragraph 89, A/Conf.171/13.

Untied Nation-Habitat (2008). State of the world's cities 2008/2009harmonious cities, London, Sterling, VA: United Nations Human Settlements Program.

World Health Organization, (2009). Women and health: today's evidence tomorrow's agenda, WHO library cataloguing in publication. http://www.who.int/gender-equity-rights/knowledge/ 9789241563857/en/.

Wuyep, S.Z., Dung, V.C., Buhari, A.H., Madaki, D.H., Bitrus, B.A. (2014) .Women participation in environmental protection and management: lessons from plateau state, Nigeria, American Journal of Environmental Protection, Vol.( 2), No. (2), pp.:32-36. DOI: 10.12691/env-2-2-1. 